\title{
BMJ Open Incidence, risk factors and perinatal outcomes for placenta accreta in Australia and New Zealand: a case- control study
}

Cynthia M Farquhar, ${ }^{1}$ Zhuoyang $\mathrm{Li}^{2}{ }^{2}$ Sarah Lensen, ${ }^{1}$ Claire McLintock, ${ }^{3}$
Wendy Pollock, ${ }^{4}$ Michael J Peek, ${ }^{5}$ David Ellwood, ${ }^{6}$ Marian Knight, ${ }^{7}$
Caroline SE Homer, ${ }^{2}$ Geraldine Vaughan, ${ }^{2}$ Alex Wang, ${ }^{2}$ Elizabeth Sullivan ${ }^{2}$

\section{ABSTRACT}

To cite: Farquhar CM, Li Z, Lensen S, et al. Incidence, risk factors and perinatal outcomes for placenta accreta in Australia and New Zealand: a case-control study. BMJ Open 2017;7:e017713. doi:10.1136/ bmjopen-2017-017713

- Prepublication history for this paper is available online To view these files, please visit the journal online (http://dx.doi. org/10.1136/bmjopen-2017017713).

Received 15 May 2017 Accepted 30 August 2017

\section{CrossMark}

For numbered affiliations see end of article.

Correspondence to Dr Cynthia M Farquhar; c.farquhar@auckland.ac.nz
Objective Estimate the incidence of placenta accreta and describe risk factors, clinical practice and perinatal outcomes. Design Case-control study.

Setting Sites in Australia and New Zealand with at least 50 births per year.

Participants Cases were women giving birth ( $\geq 20$ weeks or fetus $\geq 400 \mathrm{~g}$ ) who were diagnosed with placenta accreta by antenatal imaging, at operation or by pathology specimens between 2010 and 2012. Controls were two births immediately prior to a case. A total of 295 cases were included and 570 controls.

Methods Data were collected using the Australasian Maternity Outcomes Surveillance System.

Primary and secondary outcome measures Incidence, risk factors (eg, prior caesarean section (CS), maternal age) and clinical outcomes of placenta accreta (eg CS, hysterectomy and death).

Results The incidence of placenta accreta was 44.2/100 000 women giving birth ( $95 \% \mathrm{Cl} 39.4$ to 49.5$)$; however, this may overestimated due to the case definition used. In primiparous women, an increased odds of placenta accreta was observed in older women (adjusted OR (AOR) women $\geq 40$ vs $<30$ : 19.1, $95 \% \mathrm{Cl} 4.6$ to 80.3 ) and current multiple birth (AOR: 6.1, $95 \% \mathrm{Cl} 1.1$ to 34.1$)$. In multiparous women, independent risk factors were prior CS (AOR $\geq 2$ prior sections vs $0: 13.8,95 \% \mathrm{Cl}$ 7.4 to 26.1) and current placenta praevia (AOR: $36.3,95 \% \mathrm{Cl}$ 14.0 to 93.7). There were two maternal deaths (case fatality rate $0.7 \%$ ). Women with placenta accreta were more likely to have a caesarean section (AOR: $4.6,95 \% \mathrm{Cl} 2.7$ to 7.6 ) to be admitted to the intensive care unit (ICU)/high dependency unit (AOR: $46.1,95 \% \mathrm{Cl} 22.3$ to 95.4 ) and to have a hysterectomy (AOR: 209.0, 95\% Cl 19.9 to 875.0). Babies born to women with placenta accreta were more likely to be preterm, be admitted to neonatal ICU and require resuscitation.

\section{INTRODUCTION}

Placenta accreta is an uncommon condition occurring during pregnancy which is characterised by abnormal placentation. The severity of abnormal placentation can be classified into three grades based on histopathology: the least severe and most common
Strengths and limitations of this study

- This is the first national and binational case-control study of placenta accreta in Australia and New Zealand.

- This case-control study used active surveillance of cases by dedicated researchers, limiting recall bias and errors common in administrative datasets.

- This study may have included cases which were diagnosed antenatally but which were not confirmed clinically at operation or on pathology and therefore not true cases of placenta accreta.

- Denominator data for the number of births in Australian hospitals is an estimate because of the varying start time for hospitals in the study.

presentation is placenta accreta, in which the placental villi penetrate only to the surface of the myometrium. Placenta increta is characterised by invasion of placental villi into the myometrium. The most severe form is placenta percreta, characterised by invasion of villi beyond the myometrium to the uterine serosa and in some cases involving adjacent organs such as the bladder. ${ }^{1}$ The term 'placenta accreta' refers to all three conditions in this paper. Placenta accreta is associated with major pregnancy complications such as massive blood loss and hysterectomy and is potentially life threatening. Once the diagnosis of placenta accreta is established, the decision about mode of birth requires multidisciplinary team planning and often involves complex surgery or radiological interventions to reduce maternal and neonatal morbidity. ${ }^{23}$

The incidence of placenta accreta is believed to be increasing globally. ${ }^{23}$ This is likely attributable to an increase in caesarean sections and trends towards older women giving birth, both of which are independent 
risk factors for placenta accreta. ${ }^{45}$ There are a growing number of caesarean sections in Australia and New Zealand $^{6}$; however, the epidemiology and clinical practices for managing placenta accreta in these countries has not been previously reported. The prevalence of risk factors for this condition may be different in the Australian and New Zealand population, such as the prevalence of previous caesarian births. A case-control study with active surveillance was undertaken with the aim of estimating the incidence of placenta accreta in Australia and New Zealand and describing risk factors, clinical practices and outcomes for women affected by this condition and their babies.

\section{MATERIALS AND METHODS}

A binational population-based case-control study was undertaken using the research platform of the Australasian Maternity Outcomes Surveillance System (AMOSS). AMOSS was established across maternity units in Australia and New Zealand in 2009 to study rare and serious disorders of pregnancy. ${ }^{78}$ There were six studies conducted contemporaneously including studies on: amniotic fluid embolism, antenatal pulmonary embolism, eclampsia, super obesity and peripartum hysterectomy, which used a similar study design and data collection methodology. Data were collected from participating sites, which were public and private maternity units with more than 50 births per year in Australia and New Zealand, incorporating all service levels. Australian sites $(n=269)$ progressively joined AMOSS on completion of relevant ethics and governance approvals. In New Zealand, all 24 maternity units participated (100\% of hospital births). ${ }^{8}$

Women were identified by AMOSS-participating sites from January 2010 to December 2011 (Australia) and to December 2012 (New Zealand). All AMOSS hospital-based data collectors received study information on the surveillance period, recruitment, case definition and inclusion and exclusion criteria. Central support was available for local data collectors, including confirmation that individual cases satisfied the inclusion criteria. Nominated clinicians and midwives were contacted each month using an active surveillance system, querying whether a case had occurred that month. Data collectors identified cases through multiple sources: review of routine data collection within the hospital, audit committees, clinician notification and request to clinicians of potential cases. The average monthly response rate was $91 \%$.

Cases were defined as: women giving birth who were diagnosed with placenta accreta by either antenatal imaging, at operation or by pathology specimens. The type of diagnosis was recoded according to the earliest diagnosis. For example, a case diagnosed both by antenatal imaging and by pathology specimen was coded as diagnosed by antenatal imaging. Giving birth was defined as the birth of one or more live or stillborn infants of at least $400 \mathrm{~g}$ birth weight and/or at least 20 weeks' gestation. ${ }^{910}$ The two women giving birth immediately prior to the case in the same hospital were selected as controls. Perinatal deaths included fetal deaths of at least $400 \mathrm{~g}$ birth weight or 20 weeks' gestation and neonatal deaths occurring within 28 days after birth.

Data were collected using secure, web-based forms which captured general demographic and pregnancy data and case-specific information about prior obstetric history, current pregnancy and placenta accreta diagnosis and clinical practice, such as use of hysterectomy. For controls, the outcome of hysterectomy was obtained from a free-text field on maternal morbidity and by probabilistic matching against the AMOSS hysterectomy cohort.

Data collectors at participating hospitals were contacted regarding missing data or where data were not consistent with expected values. Logic checks were run on the data to identify any impossible or improbable scenarios. Freetext responses to questions regarding medical or obstetric morbidity were classified according to International Classification of Disease 10th Revision-Australian Modification. All data were collected in a non-identifiable manner.

Ethics approval for AMOSS was granted by the New South Wales Population and Health Services Research Ethics Committee and multiple Human Research Ethics Committees across Australia and the multiregional ethics approval (MEC/09/73/EXP) in New Zealand. ${ }^{11}$

After adjusting for the phased implementation of AMOSS, there were an estimated 478820 women giving birth (486003 babies born) in Australia and 189116 (190 408 babies born) in New Zealand across the participating maternity sites during the study period. In New Zealand, these denominators were calculated from the Ministry of Health data ${ }^{12-14}$ and in Australia by using the number of days' participation in the study multiplied by number of births per day for that hospital, which gave approximate coverage ranging from $75 \%$ in 2010 to $82 \%$ in 2011 of all women giving birth in Australia, respectively. Incidence rates were calculated with 95\% CIs. Fisher's exact test, $\chi^{2}$ test, independent samples t-test and MannWhitney U-test were used to investigate differences in demographics and obstetric characteristics, maternal and perinatal outcomes between cases and the controls. Multivariate logistic regression was used to examine the risk factors for placenta accreta by parity and to compare the maternal and perinatal outcomes of cases and controls. OR, odds ratio (AOR) and $95 \% \mathrm{CI}$ were calculated. Adjustment was made for maternal age, body mass index (BMI), smoking status during pregnancy, parity, number of previous caesarean births, placenta praevia during pregnancy, multiple pregnancies and assisted reproductive technologies. Data were analysed using the Statistical Package for the Social Sciences software V. 22.0 (IBM).

\section{RESULTS}

Of the 308 cases notified to AMOSS, 295 were eligible after excluding 13 cases; 7 outside the study period, 3 duplicate notifications and 3 not satisfying the birth definition. Of the 295 cases, 227 women were from Australia and 68 
from New Zealand. Data were available for 570 controls, as the data for 20 controls was missing.

The incidence of placenta accreta for the study period was 44.2/100 000 women giving birth (95\% CI 39.4 to 49.5). The incidences in Australia and New Zealand were 47.4/100 000 (95\% CI 41.6 to 54.0) and 36.0/100 000 (95\% CI 28.4 to 45.6 ), respectively. There were 12 perinatal deaths among the cases (perinatal death rate 38.7 per 1000 births) and 10 among the controls (perinatal death rate 17.2 per 1000 births). There were two maternal deaths among the cases, resulting in a case fatality rate of $0.7 \%$. The causes of maternal death were cerebrovascular accident secondary to pulmonary embolism and catastrophic postpartum haemorrhage due to placenta accreta. There were no maternal deaths among controls.

Almost half of the cases were first diagnosed by antenatal imaging (143, 48.5\%), $132(44.7 \%)$ were first diagnosed clinically at operation, and $16(5.4 \%)$ were not diagnosed until histological confirmation following delivery; in four cases, the time of diagnosis was not reported. In total, 184 $(62 \%)$ cases were reported as being diagnosed at operation or by histology, and 107 cases reported as being diagnosed by antenatal imaging only (36\%). There were $213(72.2 \%)$ cases with placenta accreta, $37(12.5 \%)$ with placenta increta and $45(15.3 \%)$ with placenta percreta, diagnosed by at least one of antenatal imaging, operation or histology.

The median age of women with placenta accreta was 35 years (range 21-55) and the median BMI was $28 \mathrm{~kg}$ / $\mathrm{m}^{2}$ (range $16.3-57.8$ ) (table 1 ). Over $80 \%$ of placenta accreta cases had a previous birth and $68 \%$ had a previous caesarean section. Eight per cent of pregnancies among the cases were conceived following assisted reproductive technologies and $5 \%$ of the cases had current multiple pregnancies. Forty-four per cent of cases also had placenta praevia diagnosed prior to the birth (table 1).

Women with placenta accreta were more likely to be older, have a higher BMI, a previous birth, previous caesarean section, placenta praevia diagnosed prior to delivery, current multiple pregnancy and to have conceived following assisted reproductive technologies (table 1).

Multivariate analysis was conducted separately for primiparous and multiparous women, as previous caesarean section is only applicable to women with a previous birth. In primiparous women, maternal age remained an independent risk factor for placenta accreta; mothers 40 or over had more than a 19-fold higher odds of placenta accreta compared with young mothers aged less than 30 (table 2). The presence of a current multiple pregnancy was also a risk factor for placenta accreta in primiparous women (AOR: 6.1, 95\% CI 1.1 to 34.1). In multiparous women, the independent risk factors were prior caesarean section (AOR $\geq 2$ prior sections vs $0: 13.8,95 \%$ CI 7.4 to 26.1) and current placenta praevia (AOR: 36.3 , 95\% CI 14.0 to 93.7$)$. Current placenta praevia was present in $50.2 \%$ of multiparous cases, compared with $10.8 \%$ of primiparous cases.

As the management of cases is expected to differ according to the knowledge of a placenta accreta, the cases
Table 1 Demographics and obstetric characteristics

\begin{tabular}{llll} 
& Case & Control & \\
\cline { 2 - 3 } & N (\%) & N (\%) & p Value \\
\hline Total & $295(100.0)$ & $570(100.0)$ &
\end{tabular}

Country

\begin{tabular}{|c|c|c|c|}
\hline Australia & 227 (76.9) & 436 (76.5) & 0.88 \\
\hline New Zealand & $68(23.1)$ & $134(23.5)$ & \\
\hline \multicolumn{4}{|l|}{ Maternal age } \\
\hline$<25$ & $7(2.4)$ & 93 (16.3) & $<0.001$ \\
\hline $25-29$ & 44 (14.9) & $147(25.8)$ & \\
\hline $30-34$ & 94 (31.9) & 177 (31.1) & \\
\hline 35-39 & $112(38.0)$ & $121(21.2)$ & \\
\hline$\geq 40$ & 38 (12.9) & $32(5.6)$ & \\
\hline
\end{tabular}

Indigenous status (Australian only)

$\begin{array}{llll}\text { Yes } & 11(4.8) & 13(3.0) & 0.21 \\ \text { No } & 202(89.0) & 403(92.4) & \\ \text { Not stated } & 14(6.2) & 20(4.6) & \\ \text { Ethnicity (New Zealand only) } & & \\ \text { Maori } & 13(19.1) & 18(13.4) & 0.34 \\ \text { New Zealand } & 34(50.0) & 63(47.0) & \\ \text { European } & & & \\ \text { Pacific peoples } & 5(7.4) & 17(12.7) & \\ \text { Other } & 12(17.6) & 34(25.4) & \\ \text { Not stated } & 4(5.9) & 2(1.5) & \end{array}$

Body mass index $\left(\mathrm{kg} / \mathrm{m}^{2}\right)$

\begin{tabular}{|llll}
\hline$<25$ & $115(39.0)$ & $272(47.7)$ & $<0.05$ \\
$25-29.9$ & $66(22.4)$ & $128(22.5)$ & \\
$\geq 30$ & $78(26.4)$ & $112(19.6)$ & \\
\hline Not stated & $36(12.2)$ & $58(10.2)$ & \\
Smoking during pregnancy & & \\
\hline Yes & $56(19.0)$ & $97(17.0)$ & 0.45 \\
No & $215(72.9)$ & $429(75.3)$ & \\
\hline Not stated & $24(8.1)$ & $44(7.7)$ & \\
\hline Parity & & & \\
\hline 0 & $46(15.6)$ & $240(42.1)$ & $<0.001$ \\
$1-2$ & $159(53.9)$ & $274(48.1)$ & \\
$\geq 3$ & $90(30.5)$ & $56(9.8)$ & \\
\hline
\end{tabular}

Number of previous caesarean deliveries

\begin{tabular}{|c|c|c|c|}
\hline $\begin{array}{l}\text { No prior caesarean } \\
\text { delivery }\end{array}$ & 43 (14.6) & 225 (39.5) & $<0.001$ \\
\hline 1 & 89 (30.2) & $80(14.0)$ & \\
\hline 2 & $62(21.0)$ & 19 (3.3) & \\
\hline$\geq 3$ & $50(16.9)$ & $3(0.5)$ & \\
\hline $\begin{array}{l}\text { Not applicable (no } \\
\text { prior births) }\end{array}$ & $46(15.6)$ & $240(42.1)$ & \\
\hline Not stated & $5(1.7)$ & $3(0.5)$ & \\
\hline
\end{tabular}

Continued 


\begin{tabular}{|c|c|c|c|}
\hline & Case & Control & \\
\hline & $\mathbf{N}(\%)$ & N (\%) & p Value \\
\hline Yes & $188(63.7)$ & $91(16.0)$ & $<0.001$ \\
\hline No & $55(18.6)$ & $234(41.1)$ & \\
\hline $\begin{array}{l}\text { Not applicable (no } \\
\text { prior births) }\end{array}$ & $46(15.6)$ & $240(42.1)$ & \\
\hline Not stated & $6(2.0)$ & $5(0.9)$ & \\
\hline \multicolumn{4}{|c|}{ Placenta praevia during pregnancy } \\
\hline Yes & $130(44.1)$ & $8(1.4)$ & $<0.001$ \\
\hline No & $165(55.9)$ & $562(98.6)$ & \\
\hline \multicolumn{4}{|l|}{ Multiple pregnancy } \\
\hline Yes & $15(5.1)$ & $13(2.3)$ & $<0.05$ \\
\hline No & $280(94.9)$ & $555(97.4)$ & \\
\hline Not stated & $0(0.0)$ & $2(0.4)$ & \\
\hline \multicolumn{4}{|l|}{ Assisted conception } \\
\hline Yes & $24(8.1)$ & $15(2.6)$ & $<0.001$ \\
\hline No & $259(87.8)$ & $521(91.4)$ & \\
\hline Not stated & $12(4.1)$ & $34(6.0)$ & \\
\hline
\end{tabular}

were categorised by whether or not the placenta accreta was suspected prior to birth (table 3). Of the cases, 169 $(57.3 \%)$ had a placenta accreta suspected prior to birth. On average, women with a suspected placenta accreta had a more severe condition; 57 (33\%) of suspected cases had a placenta increta or percreta compared with 24 $(19.5 \%)$ of non-suspected cases. Women with suspected placenta accreta were also more likely to have had a prior caesarean section $(93 \%)$ than women with unsuspected placenta accreta (72\%).

Cases were less likely to labour than controls $(20 \%$ vs $79 \%)$; the majority of cases who laboured had an unsuspected placenta accreta (table 3). The one case with placenta accreta suspected prior to delivery that laboured had a termination of pregnancy at 20 weeks. Additionally, cases were more likely to: give birth at an earlier gestation, to have a caesarean section, to be admitted to a high dependency unit (HDU) and to have a hysterectomy. Cases with a suspected placenta accreta were more likely to undergo hysterectomy than cases in which placenta accreta was not suspected prior to delivery $(142 / 169 ; 84 \%$ vs $53 / 123 ; 43 \%$ ), and both were more likely to undergo hysterectomy than controls $(2 / 570 ; 0.4 \%$ underwent hysterectomy). In the two controls that required a hysterectomy, the underlying cause of haemorrhage was uterine atony. Of cases undergoing hysterectomy, 15 (7.7\%) had no previous birth.

After adjusting for confounding factors, cases remained more likely to have a caesarean delivery (AOR: 4.6, 95\% CI 2.7 to 7.6 ) to be admitted to the intensive care unit (ICU) / HDU (AOR: 46.1, 95\% CI 22.3 to 95.4), and to have a hysterectomy (AOR: 209.0, 95\% CI 19.9 to 875.0). These

Table 2 Risk factor analysis including cases and controls

\begin{tabular}{|c|c|c|c|c|}
\hline & \multicolumn{2}{|c|}{ Primiparous women } & \multicolumn{2}{|l|}{ Multiparous women } \\
\hline & OR $(95 \% \mathrm{Cl})$ & AOR $(95 \% \mathrm{Cl})^{*}$ & OR $(95 \% \mathrm{Cl})$ & AOR $(95 \% \mathrm{Cl}) \dagger$ \\
\hline \multicolumn{5}{|l|}{ Maternal age } \\
\hline$<30$ & Ref & Ref & Ref & Ref \\
\hline $30-34$ & $8.0(2.6$ to 24.9$)$ & 6.3 (2.0 to 20.0$)$ & 1.7 (1. to 2.7 ) & $1.7(0.9$ to 3.2$)$ \\
\hline $35-39$ & $11.0(3.5$ to 34.9$)$ & 7.0 (2.1 to 23.6$)$ & 3.1 (2.0 to 4.8$)$ & 2.7 (1.4 to 5.2$)$ \\
\hline$\geq 40$ & 30.7 (8.2 to 115.9$)$ & 19.1 (4.6 to 80.3$)$ & $3.1(1.6$ to 6.0$)$ & $2.0(0.8$ to 5.0$)$ \\
\hline \multicolumn{5}{|l|}{ Body mass index $\left(\mathrm{kg} / \mathrm{m}^{2}\right)$} \\
\hline$<25$ & Ref & Ref & Ref & Ref \\
\hline $25-29.9$ & $1.2(0.6$ to 2.6$)$ & 1.4 (0.6 to 3.2$)$ & 1.1 (0.7 to 1.8$)$ & $0.8(0.4$ to 1.4$)$ \\
\hline$\geq 30$ & 0.7 (0.3 to 2.0$)$ & 0.7 (0.2 to 2.2$)$ & 1.4 (0.9 to 2.1$)$ & 0.8 (0.5 to 1.4$)$ \\
\hline Smoking during pregnancy & $0.2(0.1$ to 1.0$)$ & $0.4(0.1$ to 1.8$)$ & 1.3 (0.9 to 2.0$)$ & $1.3(0.7$ to 2.4$)$ \\
\hline \multicolumn{5}{|l|}{ Number of previous caesarean births } \\
\hline No prior caesarean delivery & n.a & n.a & Ref & Ref \\
\hline 1 & n.a & n.a & $5.8(3.7$ to 9.1$)$ & $3.7(2.2$ to 6.3$)$ \\
\hline$\geq 2$ & n.a & n.a & 24.8 (14.3 to 43.1$)$ & 13.8 (7.4 to 26.1$)$ \\
\hline Placenta praevia during pregnancy & 9.6 (2.2 to 41.9$)$ & $3.0(0.6$ to 15.2$)$ & 64.9 (25.9 to 162.5$)$ & $36.3(14.0$ to93.7) \\
\hline Multiple pregnancy & 14.2 (3.5 to 57.2$)$ & $6.1(1.1$ to 34.1$)$ & 1.1 (0.4 to 2.7$)$ & 1.5 (0.5 to 4.9$)$ \\
\hline Assisted conception & $5.4(2.2$ to 13.1$)$ & $1.5(0.5$ to 5.1$)$ & $4.4(1.4$ to 13.7$)$ & 2.6 (0.6 to 11.2$)$ \\
\hline
\end{tabular}

*Adjusted for maternal age, body mass index, smoking, placenta praevia during pregnancy, multiple pregnancy and assisted conception. †Adjusted for maternal age, body mass index, smoking, number of previous caesarean deliveries, placenta praevia during pregnancy, multiple pregnancy and assisted conception

AOR, adjusted OR; n.a., not applicable; Ref, reference value. 
Table 3 Labour, birth and maternal morbidity among cases with suspected and unsuspected placenta accreta prior to delivery and controls

\begin{tabular}{|c|c|c|c|c|c|}
\hline & \multicolumn{3}{|l|}{ Case } & \multirow[b]{2}{*}{ Control $(n=570)$} & \multirow[b]{3}{*}{ p Value* } \\
\hline & $\begin{array}{l}\text { PA suspected } \\
\text { antenatally } \\
(\mathrm{n}=169)\end{array}$ & $\begin{array}{l}\text { PA not suspected } \\
\text { antenatally } \\
(n=123)\end{array}$ & Totalt $(n=295)$ & & \\
\hline & $\mathbf{N}(\%)$ & $\mathrm{N}(\%)$ & $\mathbf{N}(\%)$ & $\mathbf{N}(\%)$ & \\
\hline \multicolumn{6}{|l|}{ Did the woman labour } \\
\hline Yes & $7(4.1)$ & $51(41.5)$ & $59(20.0)$ & $451(79.1)$ & \multirow[t]{2}{*}{$<0.001$} \\
\hline No & $162(95.9)$ & $72(58.5)$ & $236(80.0)$ & $117(20.5)$ & \\
\hline Not stated & $0(0.0)$ & $0(0.0)$ & $0(0.0)$ & $2(0.4)$ & \\
\hline \multicolumn{6}{|l|}{ Induced labour } \\
\hline Yes & $1(14.3)$ & $16(31.4)$ & $17(28.8)$ & $116(25.7)$ & \multirow[t]{2}{*}{0.55} \\
\hline No & $5(71.4)$ & $34(66.7)$ & $40(67.8)$ & $329(72.9)$ & \\
\hline Not stated & $1(14.3)$ & $1(2.0)$ & $2(3.4)$ & $6(1.3)$ & \\
\hline Gestation at birth, weeks, median & 35.0 & 38.0 & 36.0 & 39.0 & $<0.001$ \\
\hline \multicolumn{6}{|l|}{ Method of birth } \\
\hline Unassisted vaginal birth & $1(0.6)$ & $30(24.4)$ & $31(10.5)$ & $314(55.1)$ & \multirow[t]{4}{*}{$<0.001$} \\
\hline Instrumental vaginal birth & $0(0.0)$ & $5(4.1)$ & $5(1.7)$ & $71(12.5)$ & \\
\hline Planned caesarean birth & $140(82.8)$ & $50(40.7)$ & $190(64.4)$ & $107(18.8)$ & \\
\hline Unplanned caesarean birth & $28(16.6)$ & $38(30.9)$ & $69(23.4)$ & $77(13.5)$ & \\
\hline Not stated & $0(0.0)$ & $0(0.0)$ & $0(0.0)$ & $1(0.2)$ & \\
\hline \multicolumn{6}{|l|}{ Admission to ICU } \\
\hline Yes & $65(38.5)$ & $40(32.5)$ & $105(35.6)$ & $6(1.1)$ & \multirow[t]{2}{*}{$<0.001$} \\
\hline No & $104(61.5)$ & $81(65.9)$ & $188(63.7)$ & 564 (98.9) & \\
\hline Not stated & $0(0.0)$ & $2(1.6)$ & $2(0.7)$ & $0(0.0)$ & \\
\hline \multicolumn{6}{|l|}{ Admission to HDU } \\
\hline Yes & $68(40.2)$ & $32(26.0)$ & $101(34.2)$ & $8(1.4)$ & \multirow[t]{2}{*}{$<0.001$} \\
\hline No & $100(59.2)$ & $89(72.4)$ & $191(64.7)$ & $562(98.6)$ & \\
\hline Not stated & $1(0.6)$ & $2(1.6)$ & $3(1.0)$ & $0(0.0)$ & \\
\hline \multicolumn{6}{|l|}{ Had hysterectomy } \\
\hline Yes & $142(84.0)$ & $53(43.1)$ & $196(66.4)$ & $2(0.4)$ & \multirow[t]{2}{*}{$<0.001$} \\
\hline No & $27(16.0)$ & $69(56.1)$ & 98 (33.2) & $568(99.6)$ & \\
\hline Not stated & $0(0.0)$ & $1(0.8)$ & $1(0.3)$ & $0(0.0)$ & \\
\hline \multicolumn{6}{|l|}{ Maternal death } \\
\hline Yes & $1(0.6)$ & $1(0.8)$ & $2(0.7)$ & $0(0.0)$ & \multirow[t]{2}{*}{0.12} \\
\hline No & $168(99.4)$ & $122(99.2)$ & 293 (99.3) & $570(100.0)$ & \\
\hline
\end{tabular}

${ }^{*}$ Total number of cases versus control.

†Includes three cases where it was not known whether PA was suspected prior to birth.

ICU, intensive care unit; HDU, high dependency unit; PA, placenta accreta.

analyses were adjusted for maternal age, BMI, smoking, number of previous caesarean sections, placenta praevia diagnosed prior to delivery, multiple pregnancy and use of assisted reproductive technologies.

Babies born to mothers with placenta accreta were more likely to be preterm (median gestational age at birth 36 vs 39 weeks) and have lower birth weights, with $40 \%$ vs $9 \%$ of babies born weighing $2500 \mathrm{~g}$ or less (table 4 ). These babies were also more likely to have an Apgar score of 7 or less
5 min after birth, require resuscitation and to be admitted to a neonatal intensive care unit (NICU). Among cases, there was a higher chance of being discharged to another health facility and of neonatal death.

In the multivariate analysis, the following baby's outcomes remained significantly associated with placenta accreta: preterm birth (AOR: $5.095 \%$ CI 3.2 to 7.8), low birth weight (AOR: $5.0,95 \%$ CI 2.9 to 8.4 ), admission to NICU (AOR: 4.4, 95\% CI 2.8 to 6.9), Apgar 5 min $<7$ (AOR: 
Table 4 Perinatal outcomes among births born to women with suspected and unsuspected placenta accreta prior to delivery and controls

\begin{tabular}{|c|c|c|c|c|c|}
\hline & \multicolumn{3}{|l|}{ Case } & \multirow[t]{2}{*}{ Control (n=582) } & \multirow[t]{2}{*}{ p Value ${ }^{\star}$} \\
\hline & $\begin{array}{l}\text { PA suspected } \\
\text { antenatally }(n=174)\end{array}$ & $\begin{array}{l}\text { PA not suspected } \\
\text { antenatally }(n=133)\end{array}$ & Total† $(n=310)$ & & \\
\hline & N (\%) & $\mathbf{N}(\%)$ & $\mathbf{N}(\%)$ & N (\%) & \\
\hline Fetal deaths & $5(2.9)$ & $4(3.0)$ & $9(2.9)$ & $5(0.9)$ & $<0.05$ \\
\hline Perinatal deaths & $7(4.0)$ & $5(3.8)$ & $12(3.9)$ & $10(1.7)$ & $<0.05$ \\
\hline \multicolumn{6}{|l|}{ Sex } \\
\hline Male & $87(50.0)$ & $55(41.4)$ & $142(45.8)$ & $281(48.3)$ & 0.53 \\
\hline Female & $84(48.3)$ & $78(58.6)$ & $165(53.2)$ & $299(51.4)$ & \\
\hline Not stated & $3(1.7)$ & $0(0.0)$ & $3(1.0)$ & $2(0.3)$ & \\
\hline $\begin{array}{l}\text { Gestational age, weeks, } \\
\text { median }\end{array}$ & 35.0 & 38.0 & 36.0 & 39.0 & $<0.001$ \\
\hline \multicolumn{6}{|l|}{ Preterm birth ( $<37$ weeks) } \\
\hline Yes & $130(74.7)$ & $50(37.6)$ & $183(59.0)$ & 77 (13.2) & $<0.001$ \\
\hline No & $43(24.7)$ & $83(62.4)$ & $126(40.6)$ & $503(86.4)$ & \\
\hline Not stated & $1(0.6)$ & $0(0.0)$ & $1(0.3)$ & $2(0.3)$ & \\
\hline Birth weight $\dagger$, g, mean & $2468.3( \pm 709.1)$ & $2870.0( \pm 847.8)$ & $2640.3( \pm 795.8)$ & $3281.4( \pm 615.8)$ & $<0.001$ \\
\hline \multicolumn{6}{|l|}{ Low birth weight $t(<2500 \mathrm{~g})$} \\
\hline Yes & $81(48.5)$ & $38(29.5)$ & $120(40.1)$ & $54(9.4)$ & $<0.001$ \\
\hline No & $85(50.9)$ & $88(68.2)$ & $175(58.5)$ & 517 (89.6) & \\
\hline Not stated & $1(0.6)$ & $3(2.3)$ & $4(1.3)$ & $6(1.0)$ & \\
\hline \multicolumn{6}{|l|}{ Small for gestational age $\dagger$} \\
\hline Yes & $8(4.8)$ & $14(10.9)$ & $22(7.4)$ & $55(9.5)$ & 0.29 \\
\hline No & $158(94.6)$ & $112(86.8)$ & 273 (91.3) & $516(89.4)$ & \\
\hline Not stated & $1(0.6)$ & $3(2.3)$ & $4(1.3)$ & $6(1.0)$ & \\
\hline \multicolumn{6}{|l|}{ Admission to NICU† } \\
\hline Yes & $130(77.8)$ & $51(39.5)$ & $183(61.2)$ & $90(15.6)$ & $<0.001$ \\
\hline No & $36(21.6)$ & 76 (58.9) & $113(37.8)$ & $479(83.0)$ & \\
\hline Not stated & $1(0.6)$ & $2(1.6)$ & $3(1.0)$ & $8(1.4)$ & \\
\hline \multicolumn{6}{|l|}{ Apgar score at $5 \min \dagger$} \\
\hline$<7$ & $59(35.3)$ & $7(5.4)$ & $66(22.1)$ & $9(1.6)$ & $<0.001$ \\
\hline $7-10$ & $106(63.5)$ & $120(93.0)$ & $229(76.6)$ & 559 (96.9) & \\
\hline Not stated & $2(1.2)$ & $2(1.6)$ & $4(1.3)$ & $9(1.6)$ & \\
\hline \multicolumn{6}{|l|}{ Resuscitation $†$} \\
\hline Yes & $99(59.3)$ & $29(22.5)$ & $130(43.5)$ & $49(8.5)$ & $<0.001$ \\
\hline No & 65 (38.9) & $96(74.4)$ & $162(54.2)$ & $520(90.1)$ & \\
\hline Not stated & $3(1.8)$ & $4(3.1)$ & $7(2.3)$ & $8(1.4)$ & \\
\hline \multicolumn{6}{|l|}{ Separation status $\dagger$} \\
\hline Discharged home & 119 (71.3) & $111(86.0)$ & $232(77.6)$ & $542(93.9)$ & $<0.001$ \\
\hline $\begin{array}{l}\text { Transferred to another } \\
\text { health facility/other }\end{array}$ & $41(24.6)$ & $16(12.4)$ & $58(19.4)$ & $28(4.9)$ & \\
\hline Neonatal death & $2(1.2)$ & $1(0.8)$ & $3(1.0)$ & $5(0.9)$ & \\
\hline Not stated & $5(3.0)$ & $1(0.8)$ & $6(2.0)$ & $2(0.3)$ & \\
\hline
\end{tabular}

${ }^{\star}$ Case versus control.

†Live births only.

NICU, neonatal intensive care unit; PA, placenta accreta. 
7.8, 95\% CI 3.1 to 19.9 ), resuscitation required (AOR: $4.5,95 \%$ CI 2.7 to 7.4 ) (table 4 ). These analyses included singleton births only and were adjusted for maternal age, BMI, smoking, number of previous caesarean sections, placenta praevia diagnosed prior to delivery and assisted reproductive technologies.

\section{DISCUSSION}

The incidence of placenta accreta identified in this study was 44.2/100 000 women giving birth. This is similar to the rates reported previously from single-centre studies in individual hospitals in New Zealand $(60.2 / 100000)^{15}$ and Australia $(38.8 / 100000) .{ }^{16}$ This paper is the first to report on the national incidence of placenta accreta in both Australia and New Zealand.

The rates of placenta accreta reported previously vary markedly, both across geographic populations and as a result of different definitions of 'placenta accreta'. The highest incidence has been reported in Israel at $900 / 100000^{17}$ and a lower rate of 40/100 000 has been reported in the $\mathrm{USA}^{18} \mathrm{~A}$ review including 34 studies reported an average incidence of 189/100 000. ${ }^{4}$ More recently, the incidence of placenta accreta reported in the national United Kingdom Obstetric Surveillance System (UKOSS) was 17/100 000 women giving birth, from cases collected over a 12-month period in 20102011. ${ }^{19}$ Both UKOSS and AMOSS are case-control studies that employed national active surveillance of cases. The UKOSS methods defined placenta accreta as 'diagnosed histologically following hysterectomy or post-mortem or an abnormally adherent placenta, requiring active management, including conservative approaches where the placenta is left in situ', whereas the AMOSS study also included cases of diagnosis by antenatal imaging. It is possible that some cases included in this study were diagnosed at antenatal imaging and not found to have placenta accreta at the time of birth, which is not uncommon. ${ }^{3}{ }^{20}$ Of the 295 included cases, $107(36 \%)$ were recorded as diagnosed by antenatal imaging only, with no recorded confirmation of placenta accrete at delivery. Reports on the accuracy of ultrasound to diagnose placenta accreta are variable; however, antenatal imaging is generally considered to have a sensitivity of $77 \%-100 \%$ and specificity of $70 \%-98 \% .{ }^{20-26}$ Further, $91 / 107(85 \%)$ of these cases underwent hysterectomy following delivery, which suggests a confirmed diagnosis of placenta accreta, given that only $2 / 570 ; 0.4 \%$ of controls underwent hysterectomy. This provides some reassurance that included cases had clinical placenta accreta, although it remains a possibility that the cases may have included some women who did not have confirmed placenta accreta, and therefore this study may have overestimated the incidence of placenta accreta. It is also possible that the higher incidence of placenta accreta in Australasia as compared with the UK is a result of different exposure to risk factors. There appears to be a higher proportion of control women with risk factors for placenta accreta among the
AMOSS cohort, for example, rates of prior caesarean section ( $18 \%$ vs $15 \%)$, pregnancy conceived from assisted reproductive technologies $(2.6 \%$ vs $1 \%)$ and maternal age of 35 or older (27\% vs $24 \%$ ).

This study reports four independent risk factors for placenta accreta: older maternal age, prior caesarean section, placenta praevia diagnosed prior to birth and multiple birth; which have also been reported by other studies. ${ }^{4}$ 27-29 Previous studies have also reported risk factors that this study did not find to be independent, specifically, smoking, ${ }^{30}$ use of assisted reproductive technologies ${ }^{31}$ and sex of fetus. ${ }^{32}$ Risk factors reported previously which were not measured in this study include hypertensive disorders, previous uterine surgery, ${ }^{17} 33$ previous intrauterine procedures such as dilation and curettage $^{3435}$ and elevated second trimester serum levels of alpha-fetoprotein and free human chorionic gonadotrophin. ${ }^{32}$

Although the case definition establishes the outcome of this study as placenta accreta, it is important to consider the consequences of this condition for mother and baby. The maternal case fatality rate was $7 / 1000$, with no maternal deaths among controls. The perinatal mortality rate was 39/1000 births for cases and 17/1000 births for controls. This is slightly higher than reported previously in this population and may be a result of the small numbers of deaths in this cohort $(10 / 582)$ and the identification of controls as those delivering at the same hospital as cases, which are more likely to be tertiary hospitals. ${ }^{9}$

Maternal morbidity is high among women with placenta accreta. Just over one-third of cases $(35 \%)$ were admitted to the ICU or HDU compared with less than $2 \%$ of controls. Two-thirds of cases underwent a hysterectomy $(66.4 \%)$ compared with only $0.4 \%$ of controls. Hysterectomy can be a devastating outcome for women wishing to expand their families and is itself a significant operation. In this study, $42 \%$ of cases had an unsuspected placenta accreta, and $43 \%$ of these had an unplanned hysterectomy. Of cases undergoing a hysterectomy, $92.3 \%$ had at least one baby previously, compared with $69 \%$ having had a prior birth among cases who did not undergo a hysterectomy. This likely reflects a higher incidence of placenta accreta in women with previous births and older maternal age and may also be due to a stronger motivation to retain the uterus in women undergoing their first birth.

Women with placenta accreta were more likely to give birth earlier, and consequently the babies born to these women were more often preterm, low birth weight, required resuscitation, admitted to NICU and were more likely to die. Women with a suspected placenta accreta had a $74.7 \%$ preterm birth rate, which may reflect the management of suspected accreta with planned caesarean section; however, the preterm birth rate was also much higher among those with an unsuspected placenta accreta compared with controls (37.6\% vs $13.2 \%)$. Other studies have also reported higher preterm delivery rates and poorer outcomes for babies born to mothers with placenta accreta. ${ }^{36}$ However, this study did not find a 
higher rate of small for gestational age babies among women with placenta accreta, which has been inconsistently reported in other studies. ${ }^{437}$

Just over half of the cases included in this study had a placenta accreta suspected prior to delivery $(169 / 295$; $57.3 \%)$. This is similar to the rate of suspected placenta accreta reported in the UKOSS study of 50\%. ${ }^{19}$ It appears that women and babies with a suspected placenta accreta had inferior outcomes than those with an unknown placenta accreta, for example, higher rates of premature birth, hysterectomy and admission to ICU/HDU. This possibly reflects the higher index of suspicion around more severe cases, for example, one-third of suspected cases were diagnosed with a more severe form of placenta accreta (increta or percreta) compared with $19.5 \%$ of unsuspected cases.

The major strength of the AMOSS study design is the active surveillance for cases. Cases were captured as they occurred which minimised the risk of recall bias compared with traditional case-control studies. Although the case ascertainment is believed to be high, it is not possible to be sure of the exact level of ascertainment achieved. The study audited clinical records and did not solely depend on administrative datasets which are often unreliable, particularly for uncommon conditions.

A possible limitation of this study relates to the possible inclusion of cases which were diagnosed antenatally, but which were not confirmed clinically at operation or on pathology; however, this reflects diagnosis in real practice. Further, as it was not possible to assess how many of these cases were included, it was not possible to estimate the probability of misdiagnosis and consequent avoidable morbidity from unnecessary caesarean section. The inclusion criteria was women giving birth, defined as at least $400 \mathrm{~g}$ birth weight and/or at least 20 weeks' gestation. Therefore, any cases of accreta that resulted in an early second trimester miscarriage were not included; however, the number of these cases is expected to be few. Additionally, denominator data for the number of births in Australian hospitals is an estimate because of the varying start time for hospitals in the study. A further limitation is that information was not collected on all possible risk factors, and therefore we were not able to assess these.

Future research could explore the role of antenatal diagnosis and screening of women with risk factors for placenta accreta. A significant proportion of the cases in this study had an unsuspected placenta accreta, and nearly half of these underwent an unplanned hysterectomy. This is despite routine ultrasound for assessment of the placenta at approximately 20 weeks' gestation in these countries.

This national study from Australia and New Zealand confirms the incidence of placenta accreta in this high-income setting at approximately 1 in 2000 women giving birth. Although the condition remains rare, it is associated with a high risk of severe morbidity, and in a minority of cases, maternal death. The independent risk factors for placenta accreta in primiparous women were advanced maternal age and current multiple pregnancy. In multiparous women, previous caesarean birth and current placenta praevia were associated with an increased risk of placenta accreta. Further research on the role of antenatal diagnosis and screening in women with risk factors, particularly previous caesarean delivery, is warranted to inform clinical decision-making about place and mode of birth and to minimise risk of maternal and perinatal morbidity and mortality.

\section{Author affiliations}

${ }^{1}$ Department of Obstetrics and Gynaecology, University of Auckland, Auckland, New Zealand

${ }^{2}$ Australian Centre for Public and Population Health Research, Faculty of Health, University of Technology Sydney, Sydney, New South Wales, Australia

${ }^{3}$ Department of National Women's Health, Auckland City Hospital, Auckland, New Zealand

${ }^{4}$ Department of Nursing, Melbourne School of Health Sciences, The University of Melbourne and School of Nursing and Midwifery, Melbourne, Australia

${ }^{5}$ Department of ANU Medical School, Australian National University, Canberra, Australia

${ }^{6}$ School of Medicine, Griffith University, Gold Coast, Queensland, Australia ${ }^{7}$ National Perinatal Epidemiology Unit, Oxford, UK

Acknowledgements We would like to acknowledge the support of participating maternity units and all AMOSS data collectors and coordinators in Australia and New Zealand.

Contributors CF, MP, ES, CM, WP, DE, MK and CH conceptualised and designed the study protocol and case report forms. GV and ES managed data collection and oversaw operational aspects of the study. SL, ZL, ES and CF devised the data analysis. ZL, AW undertook the data analysis. CF, SL, ES and ZL led the drafting of the paper. All authors revised the manuscript and approved the final draft.

Funding This work was supported by the National Health and Medical Research Council (App ID 510298) from 2008 to 2012 in Australia and the Perinatal and Maternal Mortality Review Committee in New Zealand. The funding sources had no involvement in the study design, conduct, analysis, manuscript drafting or decision to publish.

Competing interests All authors have completed the ICMJE uniform disclosure form at www.icmje.org/coi_disclosure.pdf and declare: no support from any organisation for the submitted work; no financial relationships with any organisations that might have an interest in the submitted work in the previous three years; no other relationships or activities that could appear to have influenced the submitted work.

Ethics approval NSW Population and Health Services Research Ethics Committee. Provenance and peer review Not commissioned; externally peer reviewed. Data sharing statement Unpublished data are not available.

Open Access This is an Open Access article distributed in accordance with the Creative Commons Attribution Non Commercial (CC BY-NC 4.0) license, which permits others to distribute, remix, adapt, build upon this work non-commercially, and license their derivative works on different terms, provided the original work is properly cited and the use is non-commercial. See: http://creativecommons.org/ licenses/by-nc/4.0/

(C) Article author(s) (or their employer(s) unless otherwise stated in the text of the article) 2017. All rights reserved. No commercial use is permitted unless otherwise expressly granted.

\section{REFERENCES}

1. Tantbirojn P, Crum CP, Parast MM. Pathophysiology of placenta creta: the role of decidua and extravillous trophoblast. Placenta 2008;29:639-45.

2. Wu S, Kocherginsky M, Hibbard JU. Abnormal placentation: twentyyear analysis. Am J Obstet Gynecol 2005;192:1458-61.

3. Eller AG, Porter TF, Soisson P, et al. Optimal management strategies for placenta accreta. BJOG Int J Obstet Gynaecol 2009;116:648-54.

4. Balayla J, Bondarenko HD. Placenta accreta and the risk of adverse maternal and neonatal outcomes. J Perinat Med 2013;41:141-9. 
5. Hamilton BE, Martin JA, Ventura SJ, et al. Births: preliminary data for 2004. Natl Vital Stat Rep 2005;54:1-17.

6. Ellwood D, Oats J. Every caesarean section must count. Aust NZ J Obstet Gynaecol 2016;56:450-2.

7. McDonnell N, Knight M, Peek MJ, et al. Amniotic fluid embolism: an Australian-New Zealand population-based study. BMC Pregnancy Childbirth 2015;15:352.

8. Sullivan EA, Dickinson JE, Vaughan GA, et al. Maternal super-obesity and perinatal outcomes in Australia: a national population-based cohort study. BMC Pregnancy Childbirth 2015;15:322.

9. PMMRC. Tenth annual report of the perinatal and maternal mortality review committee reporting mortality 2014 . 2016.

10. Li Z, Zeki R, Hilder L, et al. Australia's mothers and babies. Perinatal statistics 2013.

11. Vaughan G, Pollock W, Peek MJ, et al. Ethical issues: the multicentre low-risk ethics/governance review process and AMOSS. Aust N Z J Obstet Gynaecol 2012;52:195-203.

12. Ministry of Health. Maternity tables 2011, 2014.

13. Ministry of Health. Report on maternity, 2010, 2012.

14. Ministry of Health. Report on Maternity, 2012, 2015.

15. Wong HS, Hutton J, Zuccollo J, et al. The maternal outcome in placenta accreta: the significance of antenatal diagnosis and nonseparation of placenta at delivery. N Z Med J 2008;121:30-8.

16. Grace Tan SE, Jobling TW, Wallace EM, et al. Surgical management of placenta accreta: a 10-year experience. Acta Obstet Gynecol Scand 2013:92:445-50.

17. Gielchinsky Y, Rojansky N, Fasouliotis SJ, et al. Placenta accreta--summary of 10 years: a survey of 310 cases. Placenta 2002;23:210-4.

18. Miller DA, Chollet JA, Goodwin TM. Clinical risk factors for placenta previa-placenta accreta. Am J Obstet Gynecol 1997;177:210-4.

19. Fitzpatrick KE, Sellers S, Spark $P$, et al. Incidence and risk factors for placenta accreta/increta/percreta in the UK: a national case-control study. PLoS One 2012;7:e52893.

20. Warshak CR, Eskander R, Hull AD, et al. Accuracy of ultrasonography and magnetic resonance imaging in the diagnosis of placenta accreta. Obstet Gynecol 2006;108:573-81.

21. Bowman ZS, Eller AG, Kennedy AM, et al. Accuracy of ultrasound for the prediction of placenta accreta. Am J Obstet Gynecol 2014;211:177.e1-177.e7.

22. Chou MM, Ho ES, Lee YH. Prenatal diagnosis of placenta previa accreta by transabdominal color Doppler ultrasound. Ultrasound Obstet Gynecol 2000;15:28-35.
23. Comstock CH, Love JJ, Bronsteen RA, et al. Sonographic detection of placenta accreta in the second and third trimesters of pregnancy. Am J Obstet Gynecol 2004;190:1135-40.

24. Dwyer BK, Belogolovkin V, Tran L, et al. Prenatal diagnosis of placenta accreta: sonography or magnetic resonance imaging? $\mathrm{J}$ Ultrasound Med 2008;27:1275-81.

25. Satija B, Kumar S, Wadhwa L, et al. Utility of ultrasound and magnetic resonance imaging in prenatal diagnosis of placenta accreta: a prospective study. Indian J Radiol Imaging 2015;25:464-70.

26. Committee on Obstetric Practice. Committee opinion no. 529: placenta accreta. Obstet Gyneco 2012:207-11.

27. Yu J, Ma Y, Wu Z, et al. Endometrial preparation protocol of the frozen-thawed embryo transfer in patients with polycystic ovary syndrome. Arch Gynecol Obstet 2015;291:201-11.

28. Oyelese Y, Smulian JC. Placenta previa, placenta accreta, and vasa previa. Obstet Gynecol 2006;107:927-41.

29. Silver RM, Landon MB, Rouse DJ, et al. Maternal morbidity associated with multiple repeat cesarean deliveries. Obstet Gynecol 2006;107:1226-32

30. Ananth CV, Savitz DA, Luther ER. Maternal cigarette smoking as a risk factor for placental abruption, placenta previa, and uterine bleeding in pregnancy. Am J Epidemiol 1996;144:881-9.

31. Kaser DJ, Melamed A, Bormann CL, et al. Cryopreserved embryo transfer is an independent risk factor for placenta accreta. Fertil Steril 2015;103:1176-84

32. Hung TH, Shau WY, Hsieh CC, et al. Risk factors for placenta accreta. Obstet Gynecol 1999;93:545-50.

33. Kastner ES, Figueroa R, Garry D, et al. Emergency peripartum hysterectomy: experience at a community teaching hospital. Obstet Gynecol 2002;99:971-5.

34. Pron G, Mocarski E, Bennett J, et al. Pregnancy after uterine artery embolization for leiomyomata: the Ontario multicenter trial. Obstet Gynecol 2005;105:67-76.

35. Al-Serehi A, Mhoyan A, Brown M, et al. Placenta accreta: an association with fibroids and Asherman syndrome. J Ultrasound Med 2008;27:1623-8.

36. Gielchinsky Y, Mankuta D, Rojansky N, et al. Perinatal outcome of pregnancies complicated by placenta accreta. Obstet Gynecol 2004;104:527-30.

37. Eshkoli T, Weintraub AY, Sergienko R, et al. Placenta accreta: risk factors, perinatal outcomes, and consequences for subsequent births. Am J Obstet Gynecol 2013;208:219.e1-219.e7. 